\title{
Logística reversa: uma breve análise histórico-sociológica
}

\section{Reverse logistics: a brief historical-sociological analysis}

\section{Fernanda dos Santos Castro}

Grupo Interdisciplinar de Educação, Eletroquímica, Saúde, Ambiente e Arte (GIEESAA), Universidade Federal do Rio de Janeiro (UFRJ), DFQ, Instituto de Química.

nanda.castro97s@gmail.com

orcid.org/0000-0001-9762-5928

\section{IsabellySette Barroco}

Grupo Interdisciplinar de Educação, Eletroquímica, Saúde, Ambiente e Arte (GIEESAA), Universidade Federal do Rio de Janeiro (UFRJ), DQF, Instituto de Química.

isabellysette@gmail.com

orcid.org/0000-0002-1814-8308

\section{Priscila Tamiasso-Martinhon}

Grupo Interdisciplinar de Educação, Eletroquímica, Saúde, Ambiente e Arte (GIEESAA), Universidade Federal do Rio de Janeiro (UFRJ), DFQ, Instituto de Química. Núcleo de Estudos em Biomassa e Gerenciamento de Águas (NAB), UFF.

pris-martinhon@hotmail.com orcid.org/0000-0001-6141-3755

\section{Angela Sanches Rocha}

Grupo Interdisciplinar de Educação, Eletroquímica, Saúde, Ambiente e Arte (GIEESAA), Núcleo de Estudos em Biomassa e Gerenciamento de Águas (NAB), UFF, Universidade do Estado do Rio de Janeiro (UERJ), DFQ, Instituto de Química.

angela.sanches.rocha@gmail.com orcid.org/0000-0002-3575-4844

\section{Celia Regina Sousa}

Grupo Interdisciplinar de Educação, Eletroquímica, Saúde, Ambiente e Arte (GIEESAA), Universidade Federal do Rio de Janeiro (UFRJ), DFQ, Instituto de Química. Núcleo de Estudos em Biomassa e Gerenciamento de Águas (NAB), UFF. 
Resumo. Questões ambientais têm apresentado grande visibilidade na sociedade contemporânea devido a problemas oriundos do alto consumo e descarte incorreto de produtos tecnológicos. Estes rejeitos liberam substâncias altamente poluentes na natureza, colocando em risco os diversos ecossistemas e a biota humana. Como consequência, há um crescente número de pesquisas buscandoprocessos mais eficientes e ecologicamente corretos, que possam suprir as carências existentes no cenário socioambiental. O presente estudo promove uma análise no âmbito histórico e sociológico acerca do aprimoramento de conceitos como Gestão Ambiental e Logística Reversa e a sua eventual aplicabilidade no tratamento de insumos e no processo de reciclagem no âmbito da mitigação dos danos ambientais gerados pelos rejeitos contemporâneos.

Palavras-chave: Educação. História. Sociologia. Logística reversa.

\begin{abstract}
Environmental issues have shown great visibility in contemporary society due to problems arising from high consumption and incorrect disposal of technological products. These wastes release highly polluting substances into the nature, endangering several ecosystems and the human biota. Consequently, there is a growing number of studies requesting more efficient and ecologically correct processes that can meet the existing needs in the socio-environmental scenario. This study promotes an analysis in the historical and sociological scope about the improvement of concepts such as Environmental Management and Reverse Logistics and their possible applicability in the treatment of inputs and in the recycling process in the context of mitigating environmental damage generated by contemporary residues.
\end{abstract}

Keywords: Education. History. Sociology. Reverse logistic.

Recebido: 01/10/2018 Aceito: 27/10/2018 Publicado: 05/11/2018

\title{
1. Introdução
}

Alguns fatores, como a crescente degradação do ecossistema por meio do consumo irresponsável de recursos naturais e a destinação inadequada de resíduos sólidos contaminantes, têm despertado o interesse da sociedade o que, consequentemente, promovediscussões acerca da necessidade de implantação de uma nova gestão ambiental. Gestão Ambiental (GA) é um conceito que tem sido ampliado com o passar do tempo, sendo concebido como um termo muito mais amplo do que apenas a gerência de um desenvolvimento sustentável (MOURÃO \& SEO, 2012). Os temas de GA e do Desenvolvimento Sustentável direcionados ao âmbito mundial surgiram a partir da ocorrência de três conferências. A Conferência de Biosfera em 1968 sediada em Paris, que 
promoveu o despertar da necessidade de conscientização ecológica. A segunda, denominada de Conferência das Nações Unidas sobre o Meio Ambiente, ocorrida em Estocolmo (1972), promoveu o debate acerca das questões ambientais para as organizações internacionais. Já a terceira, nomeada de Conferência sobre o Meio Ambiente e Desenvolvimento realizada no Rio de Janeiro, no ano de 1992, deu origem a dois documentos, A Carta da Terra e a Agenda 21 que tinham por objetivo estabelecer programas de preservação socioambientais (VIEIRA et al., 2009).

Entre as medidas adotadas pelas organizações e empresas em busca de uma renovada e eficiente gestão ambiental, encontra-se a Logística Reversa (LR), um importante instrumento em estudo, o qual objetiva, por meio do tratamento adequado, reinserir produtos, antes descartados e/ou ineficientes, na cadeia econômica, seja em seu próprio ciclo ou em outros ciclos produtivos, a fim de reduzir o descarte de poluentes e incentivar o consumo consciente (MUELLER, 2005).

O objetivo do presente trabalho é analisar o sistema de logística reversa e de gestão ambiental sob uma perspectiva histórico-sociológica, avaliando suas fragilidades e potencialidades, promovendo a reflexão sobre o tema e contribuindo assim para o desenvolvimento de futuros estudos acerca da reciclagem e reaproveitamento de insumos.

\section{Metodologia}

Como fonte de pesquisa para o embasamento teórico do estudo qualitativo supracitado utilizou-se, principalmente, os bancos de dados disponibilizados pela Web of Science, Scielo e Google Acadêmico. A pesquisa base consistia na análise prévia do sistema acerca das palavras utilizadas para a busca, de modo que, esta investigação foi restrita a aspectos inseridos nos campos de estudo pertencente às áreas de Química Verde, Meio Ambiente, História e Sociologia.

\section{Resultados e Discussão}

Dar-se-á início à abordagem dos resultados provenientes da pesquisa supracitada, com a questão evolucional de GA. Segundo Andrade, Tachizawa e Carvalho (2006), a gestão ambiental envolve a passagem de pensamento mecanicista para o pensamento sistêmico, ou seja, a percepção do mundo como máquina deu lugar à percepção do mundo como um organismo vivo. Pode-se fazer um paralelo desta perspectiva com a ideologia de Organismo Biológico de Durkheim, em que os integrantes que compõem uma sociedade atuam como partes que colaboram para o funcionamento do todo, ou seja, todos direcionam suas ações em busca de um bem geral. Além disso, ele propõe que todos os indivíduos são dotados de moral, mas diferentemente do que se imagina, essa moral representa a negação do individual e a doação do indivíduo para o todo social (GOMES, 2005). Dessa forma, inferese que a sociedade está perpassada de laços de solidariedade e por isso a mesma não representa a soma das consciências individuais, mas sim a expressão da consciência coletiva. 
À vista disso, é importante ressaltar que, dentre os sistemas vivos que compõem uma gestão ambiental estão incluídos as empresas, as comunidades/clientes e o Estado, de modo que cada instância possui seu papel e que juntos promoveriam uma política concisa, visando não apenas às suas necessidades primárias, mas também à preservação ambiental em escala mundial.

Com os eventuais aprimoramentos acerca da GA, evidenciou-se uma ampliação da definição de Logística Reversa que, inicialmente, em seu conceito mais simples, estabelecido na década de 80 , consistia na transposição de materiais do ponto de consumo ao ponto de origem (RODRIGUES et al., 2002). Já segundo o Conselho de Gestão da Logística (CLM - CouncilofLogistics Management) (KOPICKI et al., 1993), LR seria um termo amplo que estaria relacionado às habilidades e atividades envolvidas no gerenciamento de redução, movimentação e disposição de produtos e embalagens. Contudo, este conceito não leva em consideração fatores outros como reutilização, reciclagem de produtos ou qualquer retorno desses ao ciclo de vida produtivo, os quais tornam essa ideologia tão importante como um mecanismo contrário à degradação ambiental.

Assim, no Brasil, no ano de 2007 é estabelecido o projeto de lei de $\mathrm{n}^{\circ} 1991$, que conceitua a LR da seguinte forma: "A Logística Reversa tem o papel de instrumento de desenvolvimento econômico e social, caracterizada por um conjunto de ações, procedimentos e meios, destinados a facilitar a coleta e a restituição dos resíduos sólidos aos seus geradores para que sejam tratados ou reaproveitados em novos produtos, na forma de novos insumos, em seu ciclo ou em outros ciclos produtivos, visando a não geração de rejeitos." (BRASIL, 2007).

Essa definição exprime, de modo geral, o verdadeiro e completo intuito da LR, que estaria diretamente relacionado ao retorno do resíduo sólido ao ciclo produtivo ou remanufatura, de forma a reduzir a contaminação da natureza e o desperdício de insumos. À vista disso, esta ideologia permite a devolução dos produtos pelo consumidor, não apenas ao fornecedor direto, mas também ao fabricante. Uma vez feita essa devolução, tanto o fornecedor quanto o produtor primário são encarregados pela reciclagem ou reutilização do produto como insumo. Dada a adequada destinação ao produto, este poderá ser novamente remetido ao mercado consumidor, conforme mostra o esquema simplificado da LR na Figura 1. 


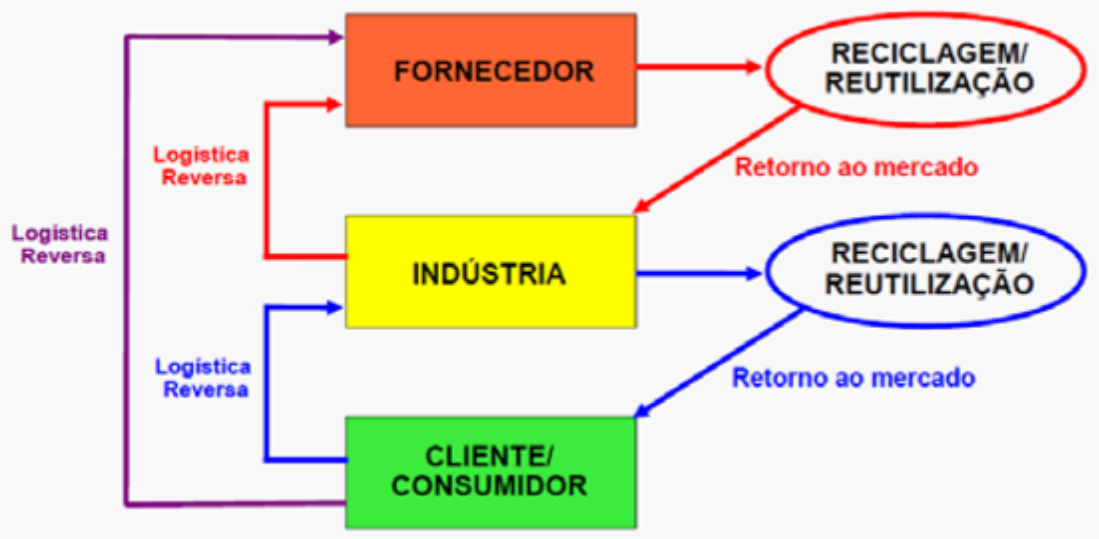

Figura 1. Esquema Simplificado da Logística Reversa

Fonte:http://www.mma.gov.br/port/conama/processos/0E732C8D/Apres_SRHUMMA_MarcosBandini_27jan10.pdf

A Logística Reversa é dividida sob dois aspectos: a LR pós consumo e a pós-venda. A primeira seria constituída pelo fluxo reverso de parte dos produtos ou materiais descartados, originados após o término de sua utilização, mas passíveis de retorno ao ciclo produtivo, sendo através de reciclagem ou reuso. Já em se tratar da segunda, caracteriza-se pelos canais de distribuição que são constituídos por diferentes formas e possibilidades de retorno de uma parcela dos produtos com pouca ou nenhuma utilização (LEITE, 2003). Tais segmentações estão associadas ao aumento do descarte, proporcional à redução do ciclo de vida dos produtos, a chamada obsolescência programada.

Contudo, existem muitas dificuldades para adoção do sistema de LR. A implantação dessa logística requer investimentos de alto custo, além de instrumentos que apenas as grandes empresas poderiam fornecer. Consequentemente, verifica-se que a decisão de adotar essa metodologia está intrinsecamente relacionada ao setor empresarial, que, através de mecanismos de apoio, subsidiaram o recolhimento dos produtos, assim como o seu armazenamento em locais adequados e o transporte de forma segura. Todavia, o custo para adotar medidas que contemplem a questão ambiental se acrescem às finanças das empresas, gastos que poucas organizações querer ter, de modo que esta política ainda é incipiente. Assim sendo, seria necessária uma parceria com os órgãos do Estado, a fim de auxiliar na elaboração de projetos específicos visando a uma melhor aplicabilidade e eficiência dessa prática, de maneira que este ficaria responsável por intermediar o contato entre o setor produtivo e o consumidor, além de informar à população como ocorrerá a administração desse fluxo inverso de materiais. É importante ressaltar que a LR depende, além de tudo, do consumidor pois, sem ele, essa prática não seria viável já que é preciso o retorno do produto para dar início a essa logística. Para tanto, torna-se fundamental a elaboração de programas de educação ambiental objetivando a propagação de um consumo consciente por parte da população. Assim, as pessoas verificaram que as práticas atuais de consumo não são coerentes com uma visão ecológica, e para tanto devem adequar suas necessidades as práticas de responsabilidade ambiental. 
Os produtos eletrônicos constam como os mais consumidos em escala mundial. Com a sua não serventia tanto pelas inovações tecnológicas quanto pela deficiência de seus mecanismos operacionais, estes são dispostos em aterros sanitários ou em ferros velhos. $\mathrm{O}$ problema reside neste descarte inadequado que vem causando problemas aos ecossistemas e às biotas que dependem dele para a manutenção de sua sobrevivência. Estudos comprovam que compostos que servem de matéria-prima para produtos tecnológicos, como metais, ao serem descartados no meio ambiente, provocam a contaminação dos sistemas aquáticos e terrestres, além da liberação de gases venenosos na atmosfera (VIEIRA et al., 2009). A exemplo da contaminação da biosfera por metais pesados, tem-se uma pesquisa realizada pela Organização Mundial da Saúde (OMS) em que se evidencia que cerca de 2000 a 3000 toneladas de mercúrio ao ano são emitidos por via industrial. Estimativas recentes indicam que das 200.000 toneladas de mercúrio emitidas em direção a atmosfera desde o final da década de XIX, por volta de $95 \%$ permanecem em solo terrestre, $3 \%$ na superfície das águas oceânicas e $2 \%$ na atmosfera (MICARONI et al., 2000).

De acordo com Gonçalves (2007), os metais pesados são causadores de problemas, não só ambientais, como interferem negativamente na saúde humana. Esses compostos podem afetar o sistema nervoso, o sistema sanguíneo e os rins. Outros, são absorvidos através da respiração e causam sintomas de envenenamento, podendo ser altamente nocivos. A exemplo do que fora supracitado, têm se: o mercúrio, um elemento de elevada toxidade e acumulação, que possui uma alta afinidade por grupos funcionais presentes em sistemas proteicos e em outras estruturas biológicas, interferindo assim no funcionamento e causando lesões nos órgãos em que se encontram; o chumbo que interfere nas funções celulares e nos órgãos críticos como a medula óssea, os rins e o sistema nervoso; o cádmio, classificado como tóxico com possível risco de efeitos irreversíveis ao ser humano, sendo classificado como agente cancerígeno, atacando principalmente o rim; o fósforo, aplicado como revestimento no interior das telas de vidro dos monitores, contém metais pesados como cádmio, zinco e vanádio, sendo assim, a desmontagem de um monitor de forma inadequada expõe a pessoa ao contato com esses elementos perigosos.

abe ressaltar que a incineração de produtos eletrônicos, como meio de tratamento dos mesmos, despeja na atmosfera substâncias tóxicas e cancerígenas, a exemplo dos metais acima citados. Por isso, a incineração jamais deve ser usada como forma de tratamento do lixo tecnológico (CÂNDIDO \& SILVA, 2007).

Sendo assim, verifica-se a necessidade de maiores investimentos para a implantação de políticas como a LR a fim de reduzir os danos ambientais ocasionados pela ausência de um tratamento adequado, tanto aos resíduos e insumos comuns gerados diariamente como a compostos de maior toxicidade que acabam dispostos incorretamente em contato com os sistemas bióticos.

\section{Conclusões}


A pesquisa realizada torna evidente que, embora seja necessário um elevado investimento inicial, uma boa administração da Logística Reversa acarretaria, subsequentemente, em uma grande economia para as empresas, além de uma melhoria significativa na qualidade de vida dos seres-vivos. Ademais, vale ressaltar que a implementação deste sistema reflete em vantagens competitivas para as empresas, ao nível de menores custos e melhoria de serviço ao consumidor.

Segundo o exposto, um dos maiores problemas que ainda persiste para a implantação dessa política, consiste na ausência de sistemas informatizados que permitam a integração da Logística Reversa ao fluxo normal de distribuição de produtos. Por essa razão empresas criam seus próprios sistemas ou terceirizam o processo para empresas especializadas, fragmentando-o ainda mais, de maneira a fragilizar sua eficiência. À vista disso, evidenciase a necessidade do estabelecimento de um mecanismo de comunicação para fins de coordenação e organização logística entre as empresas e entre o setor empresarial e o consumidor, de forma que a informação atinja a todos os extratos da sociedade.

Por fim, com o presente estudo espera-se ter contribuído significativamente tanto para uma melhor compreensão acerca das diversas esferas envolvidas no tema abordado, quanto para futuros estudos que visem a uma maior aplicabilidade de programas de preservação ambiental que envolvam a LR. Ademais, é notório que, assim como a política de logística reversa, questões como o reaproveitamento de equipamentos tecnológicos em desuso e a pesquisa por novas formas de fabricação de produtos com materiais menos danosos ao meio ambiente, devem ser melhor aprofundadas em vista da aparente potencialidade de suas aplicações no âmbito socioambiental.

\section{Financiamento}

O presente trabalho foi realizado com apoio do Conselho Nacional de Pesquisa (CNPq).

\section{Referências}

ANDRADE, R. O. B., TACHIZAWA, T. \& CARVALHO A. B. de. Gestão ambiental: enfoque estratégico aplicado ao desenvolvimento sustentável. $2^{\mathrm{a}}$ Ed. São Paulo, SP: Makrin Books, 2006.

Brasil. (2007) Projeto de Lei n 1991 de 2007 que trata sobre os resíduos sólidos. Disponível em <http://www.camara.gov.br/sileg/integras/501911.pdf $>$. Acessado em 5 de uutubro de 2018.

CÂNDIDO, C. E. de F. \& SILVA, W. C. da. Educação Ambiental: O Lixo Eletrônico. Trabalho de Conclusão de Curso - Universidade do Rio de Janeiro, Instituto de Química. Rio de Janeiro, 2007. 
GOMES, C. A. A educação em novas perspectivas sociológicas; cap. 1: Enfoques teóricos em sociologia da educação, $4^{\text {a }}$ Ed. p. 3-25, São Paulo: EPU, 2005.

GONÇALVES, A. T. O lado obscuro da High Tech na era do neoliberalismo: Seu impacto no meio ambiente. (2007) Disponível em $<$ http://lixotecnologico. blogspot.com/2007/07/o-lado-obscuro-da-high-tech-na-era-do.html>. Acessadoem 2 de Outubro de 2018.

KOPICKI, R., BERG, M. J., LEGG, L. L. Reuse and Recycling-Reverse Logistics Opportunities. O. Brooks, CLM - Council of Logistics Management, Illinois, 1993.

LEITE, P. R. Logística Reversa: Meio ambiente e Competitividade. São Paulo: Pearson Prentice Hall, 2003.

MICARONI. R. C. C. M., BUENO, M. I. M. S., JARDIM, W. F. Compostos de Mercúrio. Revisão de métodos de determinação, tratamento e descarte. Química Nova, v. 23, n. 4, p. 487-495, São Paulo, 2000.

MOURÃO, R. F, SEO, E. S. M. Logística Reversa em Lâmpadas Fluorescentes. Revista de Saúde, Meio Ambiente e Sustentabilidade, v. 7, p. 94-112, 2012.

MULLER, C. F. Logística Reversa, Meio-Ambiente e Produtividade. Estudos realizados - Grupo de Estudos Logísticos (GELOG), Universidade Federal de Santa Catarina. Santa Catarina, 2005.

RODRIGUES, D. F, RODRIGUES, G. G., LEAL, J. E. \& PIZZOLATO, N. D. Logística Reversa - Conceitos e Componentes do Sistema. XXII Encontro Nacional de Engenharia de Produção. Curitiba, 2002.

VIEIRA, K. N., SOARES, T. O. R., SOARES, L. R. A Logística Reversa do lixo tecnológico: Um estudo sobre o projeto de coleta de lâmpadas, pilhas e baterias da Braskem. Revista de Gestão Social e Ambiental, v.3, n. 3, p.120-136, 2009. 